\title{
Yulink, predicted from evolutionary analysis, is involved in cardiac function
}

\author{
Ming-Wei Kuo ${ }^{1 \dagger}$, Hsiu-Hui Tsai ${ }^{1 \dagger}$, Sheng-Hung Wang ${ }^{1}$, Yi-Yin Chen ${ }^{1}$, Alice L. Yu ${ }^{1,2}$ and John Yu ${ }^{1,3^{*}}$ (0)
}

\begin{abstract}
Background: The comparative evolutionary genomics analysis was used to study the functions of novel Ka/Ks-predicted human exons in a zebrafish model. The Yulink (MIOS, Entrez Gene: 54,468), a conserved gene from zebrafish to human with WD40 repeats at N-terminus, was identified and found to encode an 875 amino acid in human. The biological function of this Yulink gene in cardiomyocytes remains unexplored. The purpose of this study is to determine the involvement of Yulink in the functions of cardiomyocytes and to investigate its molecular regulatory mechanism.

Methods: Knockdown of Yulink was performed using morpholino or shRNA in zebrafish, mouse HL-1 cardiomyocytes, and human iPSC-derived cardiomyocytes. The expression levels of mRNA and protein were quantified by qPCR and western blots. Other methods including DNA binding, ligand uptake, agonists treatment and $\mathrm{Ca}^{2+}$ imaging assays were used to study the molecular regulatory mechanism by Yulink. Statistical data were shown as mean \pm SD or mean \pm standard error.

Results: The knockdown of yulink with three specific morpholinos in zebrafish resulted in cardiac dysfunctions with pericardial edema, decreased heart beats and cardiac output. The Yulink knockdown in mouse HL-1 cardiomyocytes disrupted $\mathrm{Ca}^{2+}$ cycling, reduced DNA binding activity of PPARY (peroxisome proliferator-activated receptor gamma) and resulted in a reduction of Serca2 (sarcoplasmic reticulum $\mathrm{Ca}^{2+}$ ATPase 2) expression. Expression of Serca2 was up-regulated by PPARY agonists and down-regulated by PPARY-shRNA knockdown, suggesting that Yulink regulates SERCA2 expression through PPARY in mouse HL-1 cardiomyocytes. On the other hand, YULINK, PPARY or SERCA2 over-expression rescued the phenotypes of Yulink KD cells. In addition, knockdown of YULINK in human iPSC-derived cardiomyocytes also disrupted $\mathrm{Ca}^{2+}$ cycling via decreased SERCA2 expression.

Conclusions: Overall, our data showed that Yulink is an evolutionarily conserved gene from zebrafish to human. Mechanistically Yulink regulated Serca2 expression in cardiomyocytes, presumably mediated through PPARy nuclear entry. Deficiency of Yulink in mouse and human cardiomyocytes resulted in irregular $\mathrm{Ca}^{2+} \mathrm{cycling}$, which may contribute to arrhythmogenesis.
\end{abstract}

Keywords: Yulink, SERCA2, PPARY, $\mathrm{Ca}^{2+}$ cycling, Cardiomyocytes

*Correspondence: johnyu@gate.sinica.edu.tw

${ }^{\dagger}$ Ming-Wei Kuo and Hsiu-Hui Tsai contributed equally to this work

1 Institute of Stem Cell and Translational Cancer Research, Chang Gung Memorial Hospital at Linkou, Taoyuan 333, Taiwan

Full list of author information is available at the end of the article

\section{Introduction}

Through comparison of the human and mouse/rat genomic sequences, Nekrutenko et al. had reported that nucleotide synonymous substitutions occurred much more frequently than nonsynonymous ones in coding regions [22]. It was predicted 13,711 novel exons that were present in both the rodent and human genomes, but the predicted transcripts remained to be validated and their biological functions remained to be demonstrated 
[20, 21]. Since 4768 of these predicted new exons had already been recognized as genes or pseudogenes, we used the remaining 8943 potential novel human exons to search for zebrafish orthologs in a zebrafish database (http://www.sanger.ac.uk/Projects/D_rerio/). Previously, we reported that 308 zebrafish orthologs displayed tissue- and/or developmental-specific expression [17]. In this early study, by a reverse screening process involving genetic knockdown (KD), a conserved gene, designated as Yulink, was identified, cloned and functionally characterized.

Here, we demonstrated that yulink promoted cardiac dysfunction in zebrafish hearts, and genetic knockdown resulted in pericardial edema, decreased beating rate and cardiac output. Knockdown of Yulink in mouse and human iPSC-derived cardiomyocytes disrupted $\mathrm{Ca}^{2+}$ cycling, reduced the DNA binding activity of PPAR $\gamma$, and resulted in a reduction of Serca2 expression. Expression of Serca 2 was up-regulated by PPAR $\gamma$ agonists and down-regulated by $P P A R \gamma$-shRNA knockdown, suggesting that Yulink regulates SERCA2 expression through PPAR $\gamma$ in mouse HL-1 cardiomyocytes. Therefore, enhancement of nuclear PPAR $\gamma$ activity may provide a mechanistic explanation for the involvement of Yulink in the regulation of Serca2 expression. Finally, knockdown of YULINK in human iPSC-derived cardiomyocytes also disrupted $\mathrm{Ca}^{2+}$ cycling via decreased SERCA2 expression. This Yulink was also found in fly as mio (Gene ID: 33399) and required for the maintenance of the meiotic cycle and oocyte identity [12]. Later, it was found as a subunit of GATOR2 complex proteins in HEK-293T cells and inhibition of GATOR2 suppressed mTORC1 signaling and GATOR2 negatively regulated GATOR1 [2]. Therefore, the Yulink is an evolutionarily conserved gene with diverse functions.

\section{Materials and methods}

\section{Bioinformatics analysis for Yulink}

Protein domains on Yulink were analyzed by SMART server (http://smart.embl-heidelberg.de) using the amino acid sequences. Alignment of protein sequences and phylogenetic tree were performed using the CLUSTALW combined with ETE3 tools on GenomeNet server (https ://www.genome.jp) with default parameters.

\section{Animals}

Breeding and maintenance of TL strain zebrafish, as well as collection and staging of embryos, were performed in accordance with standard procedures [35] and approved by the Academia Sinica Institutional Animal Care and Utilization Committee. Certain embryos were reared in zebrafish egg water [35], and treated with
0.003\% 1-phenyl-2-thiourea to inhibit pigmentation. Developmental times refer to hours (hpf) or days (dpf) post-fertilization.

\section{In situ hybridization}

Embryos were fixed in $4 \%$ paraformaldehyde buffered with $1 \times$ phosphate-buffered saline at $4{ }^{\circ} \mathrm{C}$ overnight, and proceeded to hybridized with DIG-labeled RNA antisense or control sense probes of yulink, embryos were incubated with anti-Dig antibody conjugated to alkaline phosphatase, and developed with NBT-BCIP reagents (Roche, Germany).

\section{Morpholino (MO) knockdown}

Zebrafish embryos were obtained by natural mating and microinjected with morpholino (MO) before 4-cell stage. Three different MO antisense oligonucleotides, MO (5'-GGCAGGACAGTGGCTTGTTCAGTGC-3'), MO-splicing site (5'-AGTGCCTGAGGAACCAATCGT TATT- ${ }^{\prime}$ ) and MO-start site (5'-CTGGCTTATAGCCGC TCGACATGGC-3') were designed, that targeted specifically against the $5^{\prime}$ untranslated region (UTR), the splicing site and the start site of the yulink gene, respectively.

In addition, the sequence of the $5 \mathrm{bp}$ mismatch negative control MO (yulink-5mmMO) was as follows: $5^{\prime}$-GGCtGcACAGTcGCTTcTTCAcTGC-3'. For the experiment, embryos injected with yulink-5mmMO were considered as negative control. Embryos positioned in an agarose injection chamber were injected with $\mathrm{MO}$ in $4.6 \mathrm{nl}$ using a Narishige micromanipulator and needle holder (Narishige, Japan). The phenotype was observed using a dissecting microscope (MZ-FLIII, Leica Microsystems, Germany). Images were captured with a digital camera (SPOT, DIAGNOSTIC Instruments, USA). For hemodynamic assay, images of yulink KD morphant and WT hearts were dynamically monitored and captured using a dissecting microscope and digital camera at $2 \mathrm{dpf}$. Heart rate, long and short axis length of ventricle were measured from dynamic heart images. Cardiac output value was enumerated with the following formula: heart rate $x$ (largest ventricle volume - smallest ventricle volume).

\section{qPCR for zebrafish}

Total RNA was extracted from adult zebrafish tissues using Tri-reagent (Sigma, St. Louis, MO, USA). Reverse transcription was performed using the Superscript preamplification system (Gibco BRL, USA) as described in the manufacturer's instructions. The cDNA products were amplified by PCR with specific primer sets for yulink or $\beta$-actin. The forward primer of zebrafish yulink was $5^{\prime}$-GGAACCATGTGCTGGCTGGAGG-3' and the reversed primer, $5^{\prime}$-TGACTGAACCCACGGCCCTG- $3^{\prime}$. The $\beta$-actin forward primer was 5'-TCACACCTTCTA 
CAACGAGCTGCG- $3^{\prime}$ and the reversed primer, $5^{\prime}$-GAA GCTGTAGCCTCTCTCGGTCAG-3'.

\section{Specificity of yulink gene MO}

For in vivo experiments, the yulink $5^{\prime}$-UTR (46 bp in length) and its partial coding region were amplified by PCR with specific primers (5'-TCTCGAGCTCAAGCT GTTTGCACGTCAAATCTGTCA-3' ${ }^{\prime}$ and $5^{\prime}$-GCAGAA TTCGAAGCTCAAACACTCTGGCTCATGTTT-3'), and the amplicon was ligated into a HindIII-digested pEYFP-N1 plasmid using an In-Fusion HD Cloning Kit (Clontech, USA) to generate pYulink-EYFP. Embryos were injected with pYulink-EYFP plasmid (100 pg/ embryo) alone or co-injected with pYulink-EYFP plasmid (100 pg/embryo) and either yulink-MO or yulink$5 \mathrm{mmMO}$ ( $4.6 \mathrm{ng} / \mathrm{embryo}$ ). The number of embryos expressing YFP was determined at $1 \mathrm{dpf}$.

\section{Yulink and PPARY KD in mouse HL-1 cardiomyocytes}

A pGIPZ lentiviral shRNAmir vector expressing a short hairpin RNA targeting Yulink (V2LMM_11104, mouse Yulink-shRNA) and a non-targeting control shRNA vector (Ctrl vector, RHS4346) were purchased from Open Biosystems (Huntsville, AL, USA).The TRCN0000001657 (PPAR $y$-shRNA) clone was obtained from the National RNAi Core Facility at the Institute of Molecular Biology (Academia Sinica, Taipei, Taiwan). HL-1 (mouse cardiac muscle) cells were obtained from Dr. W. Claycomb (Louisiana State University Medical Center, New Orleans, LA, USA), and were grown as previously described [32]. Stable KD cell lines were generated by lentivirus applied to HL-1 cells with $8 \mu \mathrm{g} / \mathrm{ml}$ of polybrene (Sigma, Germany). Cells were then selected using media containing puromycin $(2 \mu \mathrm{g} / \mathrm{ml}$, Sigma). RNA was isolated from cells treated with Yulink-shRNA, PPAR $\gamma$-shRNA or Ctrl vector using the Quick-RNA MiniPrep Kit (Zymo Research, USA), according to the manufacturer's instructions. The isolated RNA was reverse transcribed with the ReverTra Ace qPCR RT Kit (Toyobo, Japan).

The mRNA expression levels of Yulink, PPARy, Serca2a and GAPDH were measured by qRT-PCR using a Roche Lightcycler 480 (Roche, Germany). The Serca2a primers was designed with unique sequence at $3^{\prime}$-UTR and not expressed in Serca2b. The final qRT-PCR volume in each well was $20 \mu \mathrm{l}$ and contained $10 \mu \mathrm{l}$ of $2 \times$ THUNDERBIRD SYBR $q P C R$ Mix (Toyobo, Japan), 10 ng of cDNA, and $50 \mathrm{nM}$ of gene specific primer pairs. The primers used were as follows: Yulink-F: CAGAGTGGCATT CGCTTGTA; Yulink-R: TCATTTCATTGGTCAGCT TTTC; $P P A R \gamma-\mathrm{F}$ : GAAAGACAACGGACAAATCACC; PPAR $\gamma$-R: GGGGGTGATATGTTTGAACTTG; Serca2aF: CCTCCAGTCCTAACTTCAGTTGTT; Serca2a-R: CTGTCTACTGCTTCTGACTTCATTAAA; GAPDH-F:
GGTCCTCAGTGTAGCCCAAG; and GAPDH-R: AAT GTGTCCGTCGTGGATCT. Expression of mRNA was normalized to GAPDH in the same sample.

\section{Western blot}

Lysates of HL-1 cells treated with Yulink-shRNA, PPARyshRNA or Ctrl vector were isolated using RIPA reagent or NE-PER Nuclear and Cytoplasmic Extraction Reagents (Thermo Fisher Scientific, USA). Protein content was quantified with the BioRad DC Protein Assay (BioRad Laboratories, USA). For Western blot, protein samples were separated by $4-12 \%$ SDS-PAGE and transferred to a PVDF membrane and probed with an appropriate primary antibody at $4{ }^{\circ} \mathrm{C}$ overnight. Antibodies were acquired from the following companies: $\alpha$-Yulink (1G3) from Abnova (Taiwan), $\alpha$-GAPDH (GTX100118), $\alpha$-PPAR $\alpha \quad($ GTX28934), $\alpha$-PPAR $\delta \quad$ (GTX113250) and $\alpha$-Histone H1 (GTX114462) from GeneTex (USA), $\alpha$-SERCA2 (sc-8095) from Santa Cruz Biotechnology (USA), and $\alpha$-PPAR $\gamma$ (ab27649) from Abcam (UK). Blots were then incubated with HRP-conjugated secondary antibodies (1:5000; GeneTex) for $1 \mathrm{~h}$ at room temperature, and proteins were detected using an ECL kit (Millipore, USA). Expression of protein was normalized to GAPDH or Histone H1 in the same sample.

\section{PPARY DNA binding assays and treatment with PPAR agonists}

PPARY DNA binding activity was measured using a PPARY transcription factor assay kit (Cayman Chemical, USA). Briefly, $10 \mu \mathrm{g}$ of extracted nuclear proteins were added to wells containing immobilized dsDNA sequences corresponding to the peroxisome proliferator response element. Bound PPAR $\gamma$ was detected by the addition of specific antibodies against PPARy. Relative PPAR $\gamma$ DNA binding activity was determined by normalizing the measurements obtained for cells transfected with Yulink-shRNA to those obtained for cells treated with Ctrl vector. Rosiglitazone (Santa Cruz), pioglitazone (Sigma), GW7647 (Sigma), and GW0742 (Sigma) were stored in the dark at $-20{ }^{\circ} \mathrm{C}$. Working solutions were prepared by diluting the stock solution in media. Stable cells transfected with Yulink-shRNA or Ctrl vector were treated with or without agonist for 6 h, 12 h, or 2 days. RNA was subsequently isolated from cells using QuickRNA MiniPrep (Zymo Research, USA), according to the manufacturer's instructions.

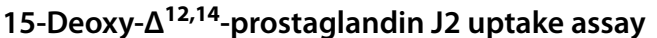

HL-1 cardiomyocytes were incubated in medium containing $1 \mu \mathrm{M}$ 15-deoxy- $\Delta^{12,14}$-prostaglandin J2-biotin (15d-PGJ2-Biotin) as a PPAR ligand for $3 \mathrm{~h}$, followed by PBS washing and trypsinization. After fixation with $4 \%$ 
PFA and staining with streptavidin-Alexa Fluor 647, the signals were analyzed by flow cytometry and immunofluorescence microscope. Approximately 10,000 cells were included in each sample for flow cytometry. The nuclei were stained with Hoechst 33342 in the immunofluorescence staining.

\section{Differentiation of human iPSC to cardiomyocytes}

Human iPSCs were split at 1:12 ratio using $0.5 \mathrm{mM}$ EDTA in PBS and grown for four days, when cells reached $85 \%$ confluence. Medium was changed to cardiomyocyte differentiation medium CDM3, which consisted of RPMI1640 basal medium, $500 \mu \mathrm{g} / \mathrm{ml}$ human albumin, and $213 \mu \mathrm{g} / \mathrm{ml} \mathrm{L}$-ascorbic acid-2 phosphate [4]. Then medium was changed every other day. For day $0-2$, medium was supplemented with $6 \mu \mathrm{M}$ GSK-3 inhibitor CHIR99021. Afterword, medium was changed to CDM3 containing $2 \mu \mathrm{M}$ Wnt signaling inhibitor Wnt-C59 on day 2-4 [4]. Starting from day 7, contracting cardiomyocytes were observed.

\section{YULINK KD in human iPSCs derived cardiomyocytes}

A pGIPZ lentiviral shRNAmir vector expressing a short hairpin RNA targeting YULINK (V3LHS_374795, human YULINK-shRNA) and a non-targeting control shRNA vector (Ctrl vector, RHS4346) were purchased from Open Biosystems (Huntsville, AL). YULINK KD cells were generated by lentivirus applied to human iPSCs derived cardiomyocytes with $8 \mu \mathrm{g} / \mathrm{ml}$ of polybrene (Sigma, Germany).

\section{$\mathrm{Ca}^{2+}$ imaging}

The control and Yulink KD cardiomyocytes were seeded in Matrigel-coated 8-well Lab Tek II chambers (Nalge Nuc international, Rochester, NY, USA). Cells were recovered after two days and loaded with $5 \mu \mathrm{M}$ Rhod-2 AM (Invitrogen) in Tyrode's solution for $15 \mathrm{~min}$ at $37^{\circ} \mathrm{C}$ as described by the manufacturer's protocol. $\mathrm{Ca}^{2+}$ imaging was conducted using a Leica SP8 confocal microscope (Wetzlar, Hesse, Germany). Spontaneous $\mathrm{Ca}^{2+}$ transients of single beating cardiomyocyte were obtained using a time-lapse line scanning recording mode (512 pixels $\times 1920$ lines) under $40 \times$ objective at room temperature, and the raw data was analyzed using Leica LAS X program. $\mathrm{Ca}^{2+}$ signal was normalized to the intracellular basal line $\left(\mathrm{F}_{0}\right)$, and the transient amplitude was expressed as $\mathrm{F} / \mathrm{F}_{0}$. In addition, the $\mathrm{\tau}(\mathrm{Tau})$ is the exponential decay of time constant for the speed of calcium uptake, which is commonly used as one method for characterizing the speed of $\mathrm{Ca}^{2+}$ recovery. A large $\tau$ value indicates a longer recovery time to baseline; the units of $\tau$ are in time (seconds). The time constant, Tau, represents the elapsed time required for the calcium amount to decay to $1 / \mathrm{e}=36.8 \%$ of the original value.

\section{Over-expression of YULINK, PPARY or SERCA2 in mouse $\mathrm{HL}-1$ cardiomyocytes}

To generate the over-expression of YULINK, PPARY or SERCA2 plasmids, the PCR products of their fulllength coding regions were generated using pEF1Flag/His-YULINK vector or cDNA from human iPSC-derived cardiomyocytes. The specific primer sets were $\quad 5^{\prime}$-tagagctagcgaattcatgagcggtaccaaacctgatattt- $3^{\prime}$ and $5^{\prime}$-tcgcggccgcggatccttatggctggacagtctctgcaggta- $3^{\prime}$ for YULINK; $\quad 5^{\prime}$-tagagctagcgaattcatgaccatggttgacacagag- $3^{\prime}$ and $5^{\prime}$-tcgcggccgcggatccctagtacaagtccttgtagatctc- $3^{\prime}$ for $P P A R \gamma ; \quad 5^{\prime}$-tagagctagcgaattcatggagaacgcgcacaccaag- $3^{\prime}$ and $\quad 5^{\prime}$-tcgcggccgcggatccttactccagtattgcaggttcc- $3^{\prime}$ for SERCA2. Then these PCR products were inserted into the lentiviral pCDH plasmid containing BFP (System Biosciences, linearized by EcoRI and BamHI double digestion) using an In-Fusion HD Cloning Kit (Clontech). All constructs were checked using Sanger sequencing (Genomics BioSci \& Tech). Over-expression of YULINK and PPARy plasmids were transfected into Yulink KD cells using lipofectamine 3000 transfection reagent (Thermo Fisher Scientific). Over-expression of SERCA2 plasmid was electroporated into Yulink KD cells using Neon electroporation system (ThermoFisher).

\section{Statistical analysis}

Some data were shown as the mean $\pm \mathrm{SD}$ whereas other values were shown as mean \pm standard error. A $p$ value or post-hoc $p$ value $<0.05$ was considered statistically significant.

\section{Results}

\section{Structure of Yulink}

Previously, we performed comparative evolutionary genomics analysis to study the functions of 13,711 novel $\mathrm{Ka} / \mathrm{Ks}$-predicted human exons using zebrafish (Danio rerio) as a model organism [17, 20-22]. Through a reverse screening process involving genetic knockdown (KD), a novel gene, designated as Yulink (MIOS, Entrez Gene: 54468), which encodes an 875 amino acid protein with WD40 repeats at $\mathrm{N}$-terminus in human and mouse (Fig. 1a). The similarities of protein sequences among Yulink genes of common experimental animals were analyzed by multiple sequence alignment using CLUSTALW (https://www.genome.jp). The classification of these homologs of Yulink was shown with a phylogenetic tree (Fig. 1b). When compared with the protein sequence of human YULINK, the phylogenetic tree indicated that YULINK proteins of rhesus and crab-eating macaque were the most similar homologs, 


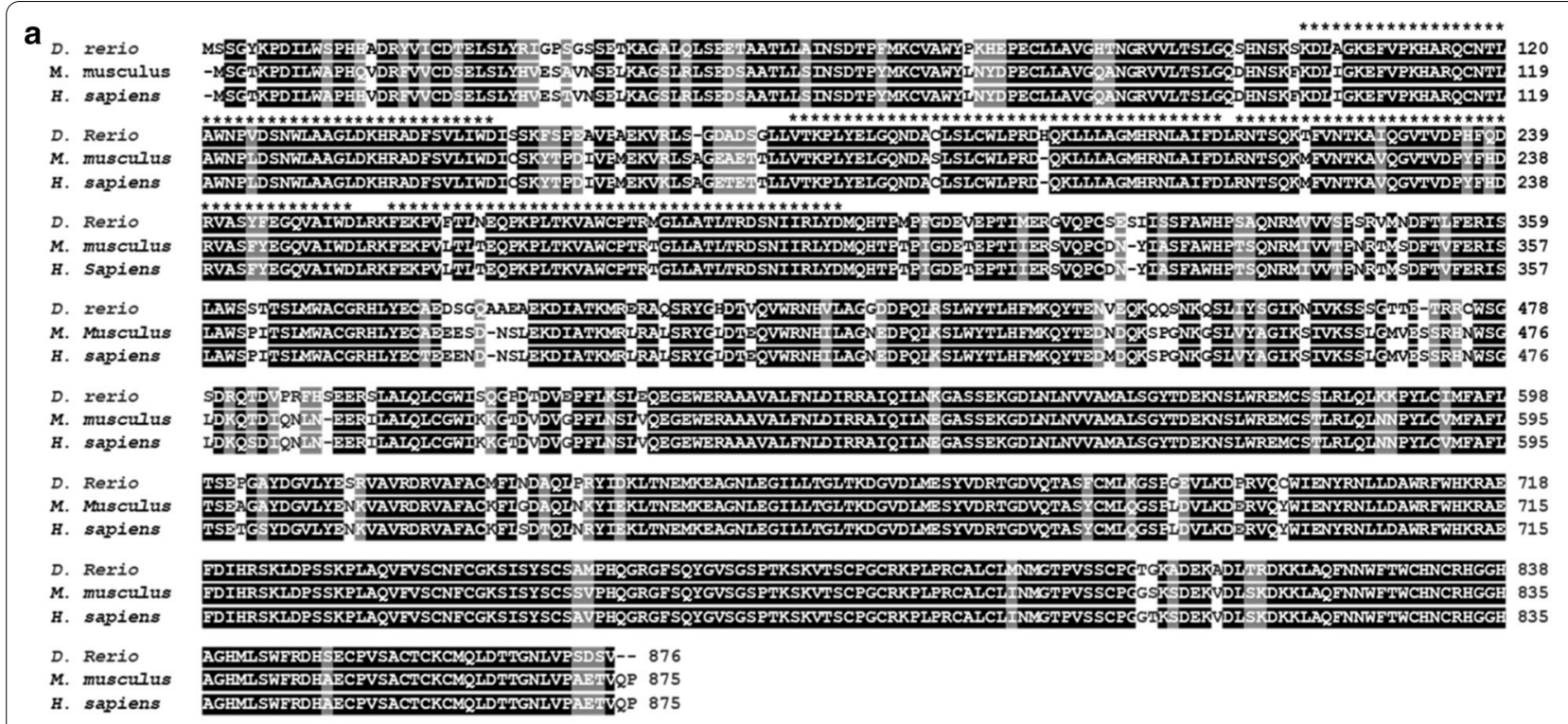

b

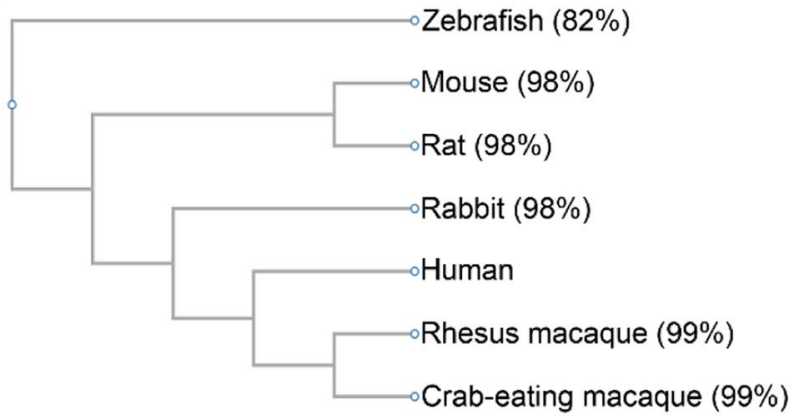

C

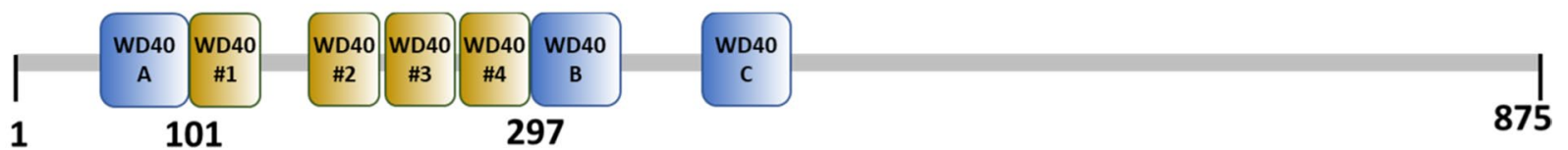

Fig. 1 Structural features of Yulink protein. a The multiple sequence alignment analysis was performed with Clustal Omega software (https://www. ebi.ac.uk/Tools/msa/clustalo/). The amino acid identity between human (NP_061878.3) and zebrafish (NP_958490.1) was 82\%, and between human and mouse (NP_663349.2) was 98\%. "Dark gray color" means that the residues in that column are identical in all sequences in the alignment. "Light gray color" means that the residues were conserved with strongly similar properties. ${ }^{* *}$ refers to WD40 repeats. b Classification and similarity of homologs of Yulink proteins. The classification of these homologs of Yulink was shown with a phylogenetic tree. The percentages of identities in amino acid sequences for homologous proteins were compared with human Yulink. c WD40 repeats within YULINK predicted by four computer servers. The prediction for WD40 repeats were based on the CDD, UniProt, SMART, and InterPro computer servers. WD40 \#1 to \#4 were the common results based on prediction using the four computer servers. The WD40 A and B were identified through the annotation of the CDD server, whereas WD40 C was found with the UniProt server

with $99 \%$ of identities in amino acid sequences (Fig. 1b). The most dissimilar homolog was yulink from zebrafish, which exhibited $82 \%$ identities (Fig. 1b). The identities for homologs of Yulink from mouse, rat and rabbit were all approximately 98\% (Fig. 1b). These analyses indicated that the Yulink gene is highly conserved in diverse species of animal, implying that the
Yulink may have potentially conserved functions from zebrafish to human.

The 3D structure of YULINK protein (Gene ID: 54468) is currently unavailable. A WD40 repeat is traditionally defined as a structural motif with about 40 amino acids composed of four $\beta$-strands which is often terminated with Trp-Asp (WD) sequence [37]. In addition, 
seven WD40 repeats can further be assembled to form a WD40 domain [37]. Such structural features were conventionally analyzed with computer servers. Currently, to explore these structural features, the following four database servers are available for annotation: (i) Conserved Domain Database (CDD, https://www.ncbi.nlm.nih.gov/ cdd), (ii) UniProt (https://www.uniprot.org), (iii) SMART (http://smart.embl-heidelberg.de), and (iv) InterPro (https://www.ebi.ac.uk/interpro) servers.

It was found that with these four computer servers, the region of AA 101 to 297 of YULINK displayed clearly four conserved WD40 repeats (i.e. WD40 \#1-\#4 in Fig. 1c, yellow). However, two additional candidates for WD40 repeats were also revealed by the Conserved Domain Database (WD40 A and B in Fig. 1c, blue). Furthermore, the UniProt server had annotated one additional WD40 repeat by (WD40 C in Fig. 1c, blue). These analyses thus suggest that YULINK may contain four conventional WD40 repeats and three additional potential candidates,

For further validation, we examined the secondary structure of YULINK in details. Since WD40 repeat is known to possess secondary structure as four $\beta$-strands, the distribution of $\beta$-strands in YULINK was analyzed with the Jpred4 (http://www.compbio.dundee.ac.uk/ jpred) (Additional file 1: Fig. S1). As shown, the first half of YULINK contains seven WD40 repeats (\#1-\#4 and A-C) as predicted by four computer servers to possess the prerequisite features. The distribution of secondary structure as analyzed by Jpred4 server further confirmed that each predicted WD40 repeat displayed three to four tandem $\beta$ strands (Additional file 1: Fig. S1); these structural features are reminiscent of the characteristics for typical WD40 repeats. In conclusions, YULINK has four conserved WD40 repeats and three additional potential WD40 repeat candidates.

\section{Specificity of yulink-MO knockdown (KD) in zebrafish morphants}

The yulink was expressed in whole zebrafish embryo ubiquitously from $0.5 \mathrm{hpf}$ (zygote stage) to $3 \mathrm{dpf}$ (larval stage) and expressed in heart region starting at 24-30 hpf (Fig. 2a). To investigate the biological function of the yulink gene, zebrafish embryos before the 4-cell stage were injected with the antisense oligonucleotide yulinkMO, which targeted against to $5^{\prime}$-UTR, to knockdown gene function. Yulink KD morphants showed small eyes, a small head, and marked pericardial edema, as compared to the wild type at $3 \mathrm{dpf}$ (Fig. 2b). Increasing the yulink-MO amount from 2.3 to $9.2 \mathrm{ng}$ caused the proportion of the severely affected embryos with pericardial edema from 6 to 54\% (Fig. 2b). We had also constructed two other MOs, which targeted against splicing site and translational start site of the yulink gene, respectively, the results are shown in Additional file 1: Fig. S2. The abnormal phenotypes (e.g. small eyes, a small head, marked pericardial edema, etc.) after treatment of these MOs were similar to those in the morphants originally observed in Fig. 2b, at wide range dosage of MOs (1-10 ng/embryo).

In addition, severely affected embryos which showed marked pericardial edema exhibited defects in blood circulation. The yulink KD morphants exhibited slower heart rates (126 beats/min), as compared to mismatch control $5 \mathrm{mmMO}$ (187 beats/min, Fig. 2c, Additional file 1: Video). Besides, the yulink KD morphants also exhibited reduced cardiac output averaged $11.7 \mu \mathrm{l} /$ $\mathrm{min}$, as compared to the $5 \mathrm{mmMO}$ averaged $42.7 \mu \mathrm{l} / \mathrm{min}$ (Fig. 2c). Loss of function for serac2a [7] or several ion channel related genes (e.g. the "hyperpolarization activated cyclic nucleotide gated potassium channel 4", hcn4 $[14,29]$, and T-type calcium channels, a1G, $a 1 H a, a 1 H b$, $a 1 l a$ and $a 1 l b$ [27]) were reported to reduce the heart rate. Therefore, specific qPCR primers were designed for these genes (Additional file 1: Fig. S3A). The expression levels of serca2a and the ion-channel related genes were found to decrease significantly in yulink KD morphants (orange color) after normalization with the internal control (bactin1) at $3 \mathrm{dpf}$ (Additional file 1: Fig. S3b, c), thus consistent with the observed slower heart rates for the yulink KD morphants.

To further confirm the above findings were not caused by off-target effect, the $5^{\prime}$-UTR of yulink and its partial coding sequences were introduced into the pEYFP-N1 plasmid to generate the pYulink-EYFP plasmid (Fig. 2d). Approximately $58 \%$ of the embryos injected with this plasmid (100 pg/embryo) exhibited EYFP fluorescence in vivo (Fig. $2 \mathrm{~d}$ ). In a parallel co-injection with yulinkMO totally suppressed EYFP expression; in contrast, the mismatch control, yulink $-5 \mathrm{mmMO}$ did not affect EYFP expression (Fig. 2d). To further assess the specificity of the yulink-MO, the ability of synthesized mouse Yulink mRNA to protect against the yulink-MO-induced changes in phenotype was determined, using the $\beta$-gal mRNA as an experimental control (Additional file 1: Fig. S4). After injection of yulink-MO into zebrafish embryos, the proportions of morphants with severe (gray color) and moderate (orange color) phenotype changes were, respectively, $65.8 \%$ and $18.6 \%$. But, co-injection of the control $\beta$-gal mRNA and yulink-MO did not change the proportions of morphants which displayed severe and moderate phenotypes (62.2\% and $15.6 \%)$; these values were similar to those observed with the injection of yulink-MO alone. However, co-injection with Yulink mRNA reduced the proportions of morphants with severe phenotype significantly to $38.7 \%$. Importantly, the 


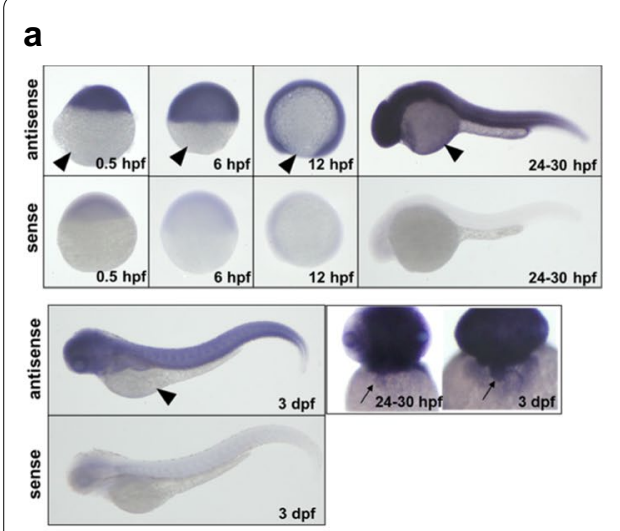

\section{b}
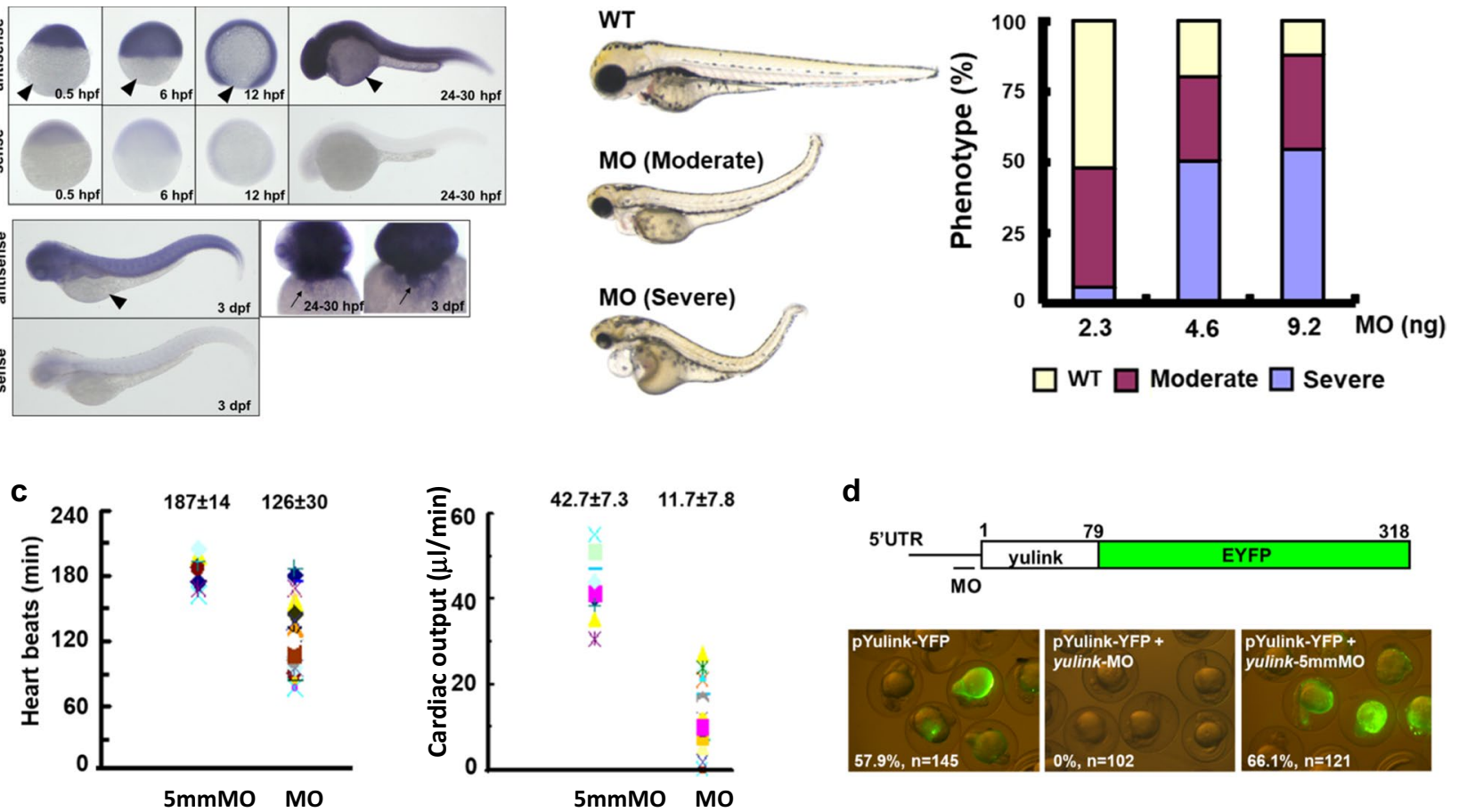

Fig. 2 Characterization of yulink-MO KD zebrafish morphants. a Expression of yulink in zebrafish using whole-mount in situ hybridization. Embryos were fixed overnight at $4{ }^{\circ} \mathrm{C}$ in $4 \%$ paraformaldehyde buffered with $1 \times$ phosphate-buffered saline (PFA/PBS). After hybridization with Dig-labeled antisense or control sense RNA probes of yulink, embryos were incubated with anti-Dig antibody conjugated to AP and developed with NBT-BCIP reagents. The yulink was expressed in whole zebrafish embryo ubiquitously from $0.5 \mathrm{hpf}$ (zygote stage) to $3 \mathrm{dpf}$ (larval stage) with lateral overview. The black arrows point to heart regions at 24-30 hpf and $3 \mathrm{dpf}$ with ventral overview. The black arrowheads point to yolk of embryos, hour post-fertilization ( $\mathrm{hpf}$ ); day post-fertilization (dpf). b After injection with yulink-MO to knockdown yulink expression, the yulink KD morphants presented with small eyes, a small head, abnormal blood circulation, and pericardial edema at $3 \mathrm{dpf}$. Increasing the yulink-MO dosage from $2.3 \mathrm{ng}$ ( $n=119)$ to $4.6 \mathrm{ng}(\mathrm{n}=119$ or $9.2 \mathrm{ng}(\mathrm{n}=156)$ caused the proportion of severely affected embryos with pericardial edema to increase from 6 to $54 \%$ (purple). c Hemodynamic changes. Yulink KD morphants had a slower heart rate and reduced cardiac output, as compared to WT embryos at 2 $\mathrm{dpf}$ (** $p<0.01$, Student's $t$ test). d Diagram of the EYFP-fusion construct with the yulink 5'-UTR region and partial coding region (amino acids 1-79). The position of the corresponding $\mathrm{MO}$ binding site is indicated by a bar. To demonstrate the specificity of the yulink-MO, embryos were injected with pYulink-EYFP plasmid (100 pg/embryo) alone, or together with yulink-MO or the mismatch control, yulink-5mmMO (4.6 ng/embryo). About $58 \%$ of embryos injected with pYulink-EYFP plasmid alone exhibited fluorescence at $1 \mathrm{dpf}$, while fluorescence was absent in embryos co-injected with yulink-MO. In contrast, co-injection with yulink-5mmMO did not affect EYFP expression

morphants with moderate or normal phenotypes were found to increase to $30.65 \%$ and $30.65 \%$, respectively (Additional file 1: Fig. S4). These results thus implied that morphants caused by injection of yulink-MO could be competed (rescued) to become the morphants with less severe (moderate) and WT phenotype with the co-injection of Yulink mRNA. It was thus concluded that Yulink is important for the heart development and cardiac function in zebrafish; but detailed characterization ... await for future electrophysiological studies.

\section{Yulink knockdown induces irregular $\mathrm{Ca}^{2+}$ cycling in mouse HL-1 cardiomyocytes}

The yulink KD morphants in zebrafish reduced the heart rates and cardiac output suggest that the Yulink may play an important role in cardiomyocytes. To investigate this possibility, mouse HL-1 cardiomyocytes were transduced with lentivirus expressing short hairpin RNA (shRNA) against Yulink. Quantitative PCR and western blotting analysis of the transduced cells confirmed a Yulink knockdown with efficiency of $\sim 50 \%$ (Fig. 3a).

Calcium $\left(\mathrm{Ca}^{2+}\right)$ plays a critical role in regulation of excitation-contraction coupling and is essential in the electrical signaling of cardiomyocytes. Abnormal $\mathrm{Ca}^{2+}$ cycling is linked to arrhythmogenesis, which is associated with cardiac disorders and heart failure [10]. Accordingly, we measure $\mathrm{Ca}^{2+}$ cycling from control and Yulink KD HL-1 cells using confocal fluorescence microscopy loaded with fluorescent $\mathrm{Ca}^{2+}$ dye Rhod-2 AM. Compared to control, Yulink KD demonstrated significant higher 

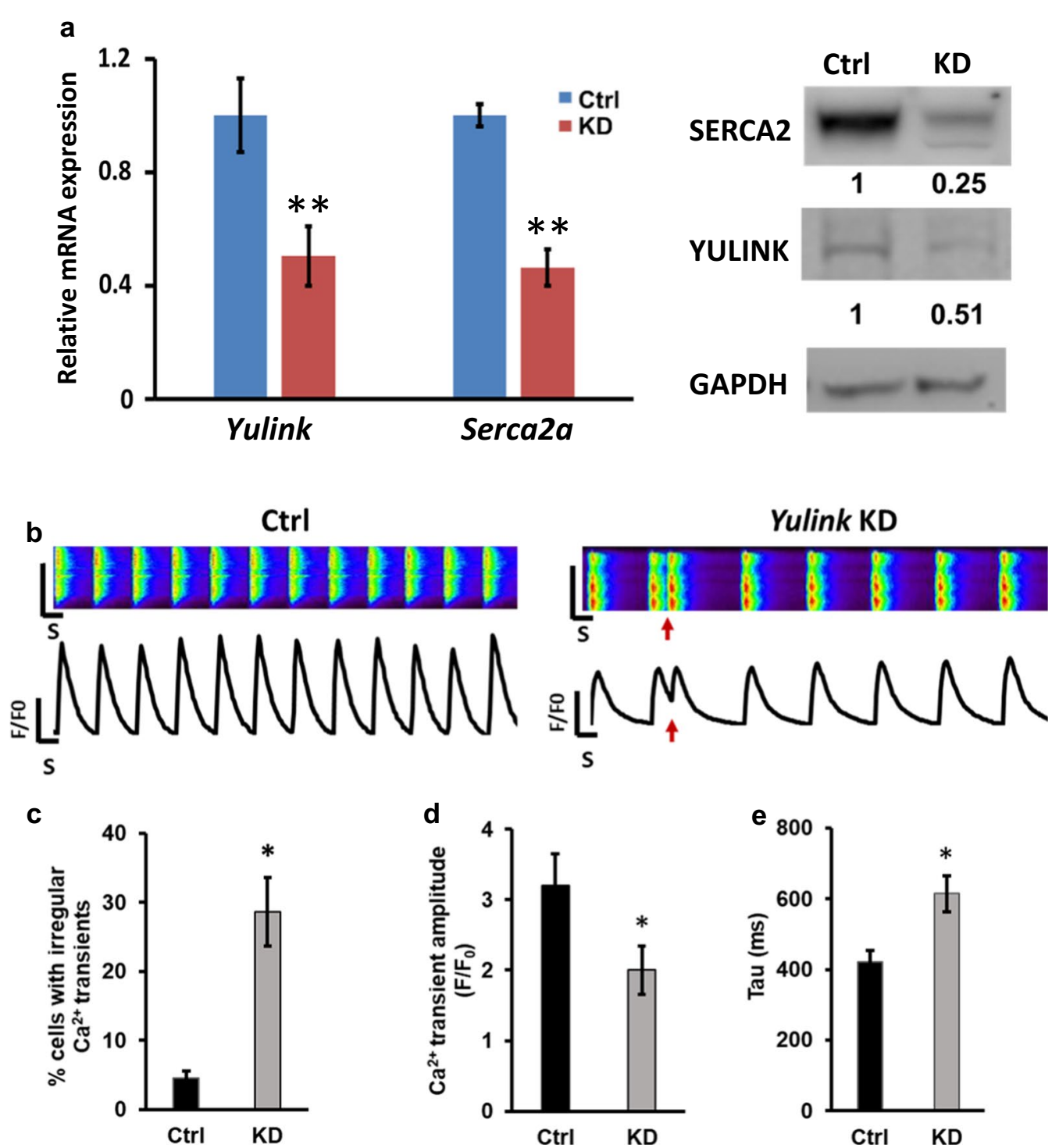

Fig. 3 Yulink KD reduced Serca2 expression and induced irregular $\mathrm{Ca}^{2+}$ cycling in mouse $\mathrm{HL}-1$ cardiomyocytes. a Representative line-scan images and spontaneous $\mathrm{Ca}^{2+}$ transient in Ctrl and Yulink KD mouse HL-1 cardiomyocytes. Red arrows indicate arrhythmia-like waveforms observed in Yulink KD HL-1 cardiomyocytes, but not in control. b Quantification of percentages for control and Yulink KD HL1 cardiomyocytes exhibiting irregular $\mathrm{Ca}^{2+}$ transients $(\mathrm{n}=40)$. c The $\mathrm{Ca}^{2+}$ transient amplitude of $\mathrm{HL}-1$ cardiomyocytes for $\mathrm{Ctrl}$ and Yulink KD confirms Yulink KD HL-1 cardiomyocytes exhibits a lower $\mathrm{Ca}^{2+}$ transient amplitude $(\mathrm{n}=40)$. $\mathbf{d}$ The time constant for $\mathrm{Ca}^{2+}$ decay (Tau) of $\mathrm{HL}-1$ cardiomyocytes for control and Yulink KD show that the time constant for $\mathrm{Ca}^{2+}$ decay is significantly larger in Yulink KD than in control HL-1 cardiomyocytes $\left(n=40,{ }^{*} p<0.05\right.$, Student's $t$ test). e HL-1 cardiomyocytes were subjected to Yulink KD using Yulink-shRNA, and the effects on Yulink and Sercaz expression were assayed by qPCR and Western blot. Relative expression values were normalized to those of cells injected with control (Ctrl) vector $\left(n=3\right.$ for each group, ${ }^{* *} p<0.01$, Student's $t$ test)

$\mathrm{Ca}^{2+}$ transient irregularities which may relate to triggered arrhythmia-like waveforms (Fig. 3b, red arrows); irregular $\mathrm{Ca}^{2+}$ transients were virtually absent in control cells (28.6\% for Yulink KD vs. 4.6\% for control, Fig. 3c).

Moreover, we also observed that the Yulink KD HL-1 cells exhibited defective intracellular $\mathrm{Ca}^{2+}$ cycling with a significantly observed reduced amplitude of $\mathrm{Ca}^{2+}$ transients $\left(\mathrm{F} / \mathrm{F}_{0}=1.87 \pm 0.31\right)$ than in control cells $(\mathrm{F} /$ $\left.\mathrm{F}_{0}=2.89 \pm 0.34\right) \quad$ (Fig. 3d). In particular, the Yulink $\mathrm{KD}$ exhibited defective intracellular $\mathrm{Ca}^{2+}$ cycling with a significantly slower $\mathrm{Ca}^{2+}$ decay rate $(615 \pm 51 \mathrm{~ms})$ than control ( $421 \pm 34 \mathrm{~ms})$ (Fig. 3e). These data suggest that knockdown of Yulink contribute to abnormal 


\section{(See figure on next page.)}

Fig. 4 Over-expression of YULINK, PPARY and SERCA2 rescued the phenotypes of mouse Yulink KD HL-1 cardiomyocytes. Control (Ctrl), YULINK, PPARY or SERCA2 plasmids (carrying BFP as indicator of expression marker) were transfected or electroporated into Yulink KD cells, and then analyzed for $\mathrm{Ca}^{2+}$ cycling using fluorescent $\mathrm{Ca}^{2+}$ dye, Rhod-2 AM. a Over-expression of YULINK or PPARY. Representative line-scan images and spontaneous $\mathrm{Ca}^{2+}$ transient in Yulink KD mouse HL-1 cardiomyocytes. Arrhythmia-like waveforms were observed in Yulink KD cardiomyocytes with Ctrl vector (red arrows). After over-expression of YULINK (YULINK-OE) or PPARY (PPARY-OE) in Yulink KD cells, normal waveforms were observed. The result of $\mathrm{Ca}^{2+}$ spark analysis was consistent with the increase of $\mathrm{Ca}^{2+}$ transient amplitudes ( $3.1 \pm 0.5$ for YULINK-OE or $3.2 \pm 0.3$ for PPARY-OE, vs. $1.9 \pm 0.35$ for Ctrl). The cells with YULINK or PPARY over-expression also exhibited a decrease of the percentages of irregular $\mathrm{Ca}^{2+}$ transients $(8 \pm 2 \%$ for YULINK-OE or $10 \pm 2 \%$ for PPARY-OE, vs. $27 \pm 3 \%$ for Ctrl). The cells with YULINK or PPARY over-expression also exhibited a reduction of the Ca ${ }^{2+}$ decay (Tau) rate ( $430 \pm 42 \mathrm{~ms}$ for YULINK-OE or $450 \pm 51 \mathrm{~ms}$ for PPARY-OE, vs. $605 \pm 47 \mathrm{~ms}$ for Ctrl). Ctrl (black bars), YULINK-OE (orange bars) and PPARY-OE (blue bars) $\left(n=40\right.$, each). ${ }^{*} p<0.05$, Student's $t$ test. $\mathbf{b}$ Over-expression of SERCA2. Representative line-scan images and spontaneous $C a^{2+}$ transients in Yulink KD mouse HL-1 cardiomyocytes. Arrhythmia-like waveforms were observed in Yulink KD cardiomyocytes with control vector (Ctrl, red arrows). After over-expression of SERCA2 (SERCA2-OE) in Yulink KD cells, normal waveforms were observed. The result of $\mathrm{Ca}^{2+}$ spark analysis was consistent with the increase of $\mathrm{Ca}^{2+}$ transient amplitudes (3.2 \pm 0.45 for SERCA2-OE vs. $2.02 \pm 0.3$ for Ctrl). The cells with SERCA2-OE also exhibited a decrease of the percentages of irregular $\mathrm{Ca}^{2+}$ transients ( $11 \pm 3 \%$ for SERCA2-OE vs. $32 \pm 5 \%$ for Ctrl). The cells with SERCA2-OE also exhibited a reduction of the Ca ${ }^{2+}$ decay (Tau) rate ( $412 \pm 50$ ms for SERCA2-OE vs. $635 \pm 78 \mathrm{~ms}$ for Ctrl). Ctrl vector (black bars), SERCA2-OE (gray bars) ( $\mathrm{n}=35$, each). ${ }^{*} p<0.05$, Student's $t$ test

intracellular $\mathrm{Ca}^{2+}$ release and arrhythmogenic phenotype in mouse HL-1 cardiomyocytes.

\section{Over-expression of YULINK rescued the phenotypes of Yulink KD HL-1 cells}

In order to study whether the over-expression (OE) of YULINK rescued the phenotypes of Yulink KD HL-1 cells, control (Ctrl) or YULINK plasmid (carrying BFP as indicator of expression marker) were transfected into Yulink KD cells, and then $\mathrm{Ca}^{2+}$ cycling were analyzed using the fluorescent Rhod-2 AM dye. In Fig. 4a, the intracellular $\mathrm{Ca}^{2+}$ cycling waveforms became normal, when these KD cells were over-expressed with YULINK, as compared to Yulink KD cells. In addition, the results of $\mathrm{Ca}^{2+}$ sparks analysis were consistent with the increase of $\mathrm{Ca}^{2+}$ transient amplitudes $(3.1 \pm 0.5$ for YULINK-OE, orange bar, vs. $1.9 \pm 0.35$ for Ctrl, black bar) (Fig. 4a). These cells with YULINK-OE also exhibited a decrease of the percentages of irregular $\mathrm{Ca}^{2+}$ transients $(8 \pm 2 \%$ for YULINK-OE, orange bar, vs. $27 \pm 3 \%$ for Ctrl, black bar) and the reduction of the $\mathrm{Ca}^{2+}$ decay rate $(430 \pm 42 \mathrm{~ms}$ for YULINK-OE, orange bar, vs. $605 \pm 47 \mathrm{~ms}$ for Ctrl, black bar) (Fig. 4a). The level of $\mathrm{Ca}^{2+}$ transient amplitudes, the percentages of irregular $\mathrm{Ca}^{2+}$ transients, and the $\mathrm{Ca}^{2+}$ decay (Tau) rate were all similar between Ctrl (Fig. 3b) and over-expression of Yulink cells. These data indicate that the Yulink-shRNA used in our studies was specific and the observed defects in cells were indeed Yulink-dependent.

\section{Knockdown of Yulink reduces Serca 2 expression in mouse HL-1 cardiomyocytes}

Several studies have suggested that expression and function of Serca 2 play a major role in defective intracellular $\mathrm{Ca}^{2+}$ cycling $[11,26,32]$. The decreased Serca2 expression may also contribute to mechanical failure in cardiomyocytes [24]. Therefore, it is hypothesized that Yulink may play a role in regulating SERCA2 expression. SERCA2a, one of the two isoforms for SERCA2, was expressed in cardiac muscle, slow-twitch skeletal muscle, and smooth muscle cells, while SERCA2b is an ubiquitous isoform expressed in muscle and non-muscle cells [25]. It was also reported that approximately $95 \%$ of the SERCA2 protein in mouse HL-1 cardiomyocytes are Serca2a [34]. To examine the Serca2a expression in the Yulink KD mouse HL-1 cardiomyocytes, we first performed quantitative PCR using specific Serca2a primers, designed based on a unique sequence at $3^{\prime}$-UTR region which were not expressed by Serca2b. As shown in Fig. 3a, there was significant reduction of Serca2a expression after Yulink KD by qPCR. Similarly, on Western blot analysis, there was also reduction of SERCA2 protein expression (Fig. 3a). Therefore, these results demonstrate that the expression of Yulink is required for Serca2 expression. These data imply that Yulink may be involved in the expression of Serca2 as well as the intracellular $\mathrm{Ca}^{2+}$ cycling in mouse HL-1 cardiomyocytes.

\section{Knockdown of Yulink blocks the entry of PPARY ligands into cells and decreases PPARY DNA binding activity in the nuclei}

The peroxisome proliferator-activated receptors (PPARs) are ligand-activated transcription factors of the nuclear receptor superfamily [13]; one member of this family, PPAR $\gamma$ has been reported to directly bind to a PPAR $\gamma$ response element within the Serca2 gene proximal promoter in pancreatic islet cells [16]. We next evaluate the PPARY DNA-binding activities in the Yulink KD cardiomyocytes using the immobilized dsDNA corresponding to the peroxisome proliferator response element. As showed in Fig. 5a, the PPARY DNA-binding amount of Yulink KD HL-1 was significantly decreased to $47 \%$ 


\section{a Over-expression of YULINK or PPAR $\gamma$}

$\mathrm{Ca}^{2+}$ transient analysis
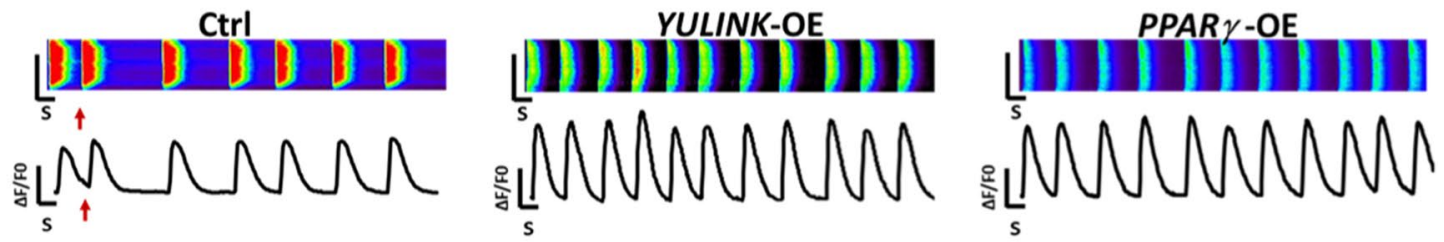

$\mathrm{Ca}^{2+}$ transient amplitude

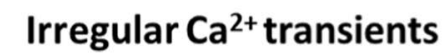

$\mathrm{Ca}^{2+}$ decay (Tau)
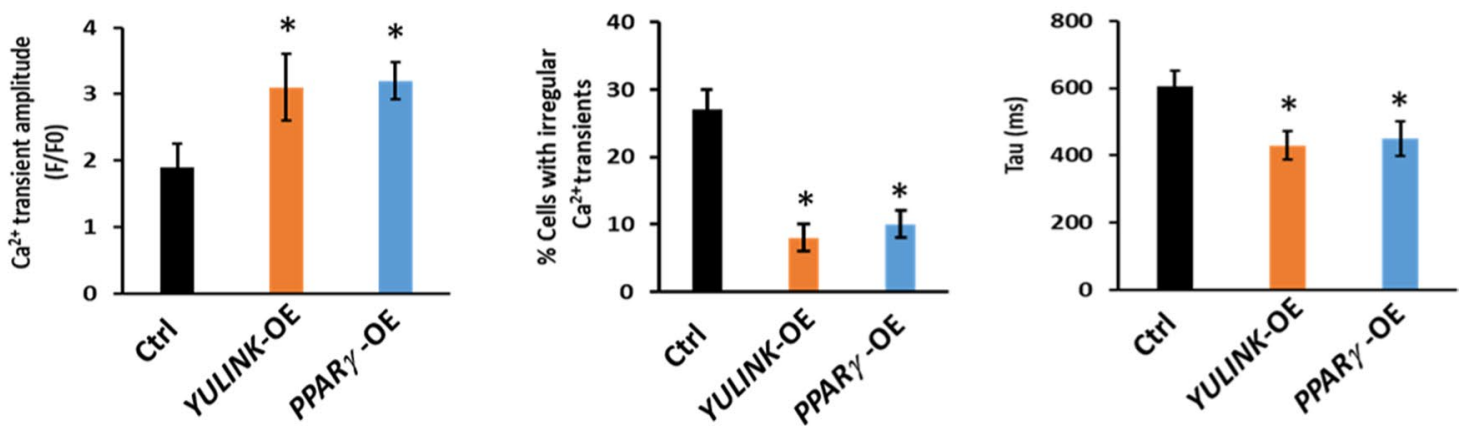

b Over-expression of SERCA2

$\mathrm{Ca}^{2+}$ transient analysis

ctrl

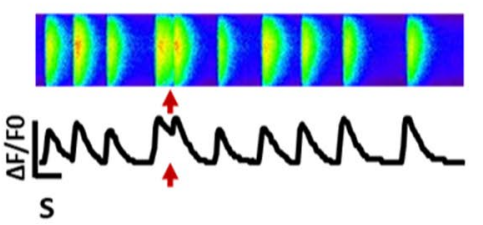

SERCA2-OE

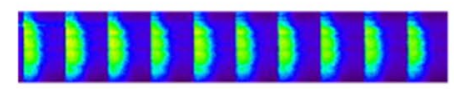

:
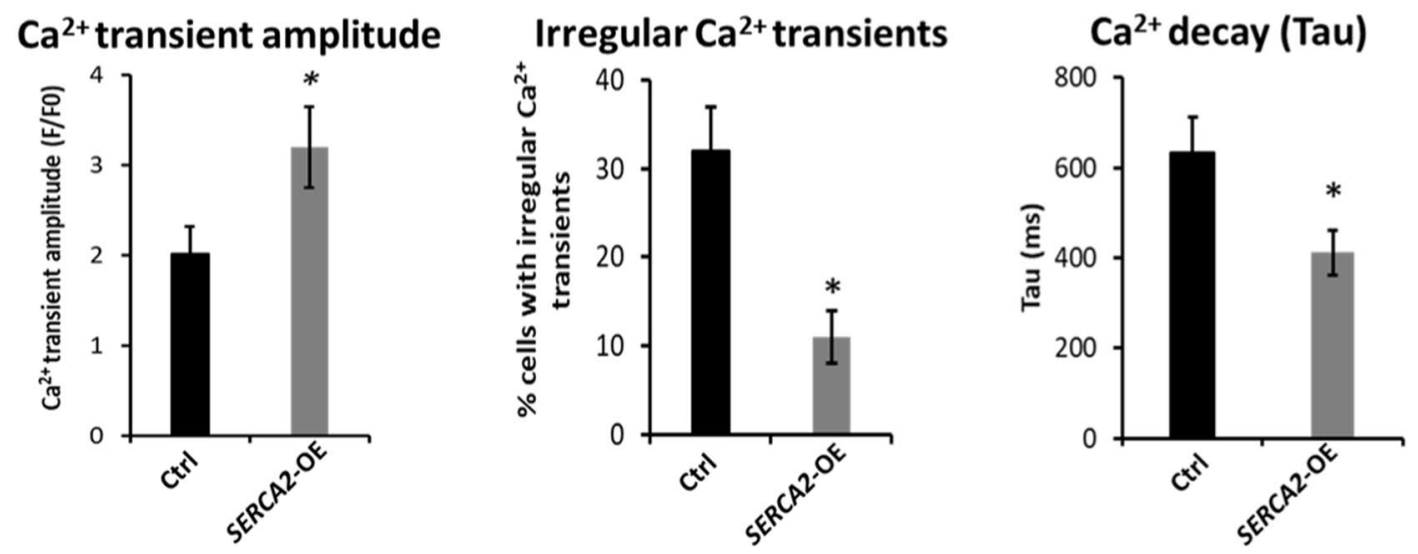

compared to control cells. Consistent with these findings, we also found that the nuclear PPARy was decreased in Yulink KD cardiomyocytes by immunofluorescence staining (Fig. 5b). Western blot analysis also showed that the nuclear PPAR $\gamma$ protein level was decreased by $85 \%$ in Yulink KD cardiomyocytes, respectively (Fig. 5c). In this assay, the decrease of PPAR $\gamma$ in lysate of Yulink KD cell nuclei also reflected a lower DNA binding activity. The 


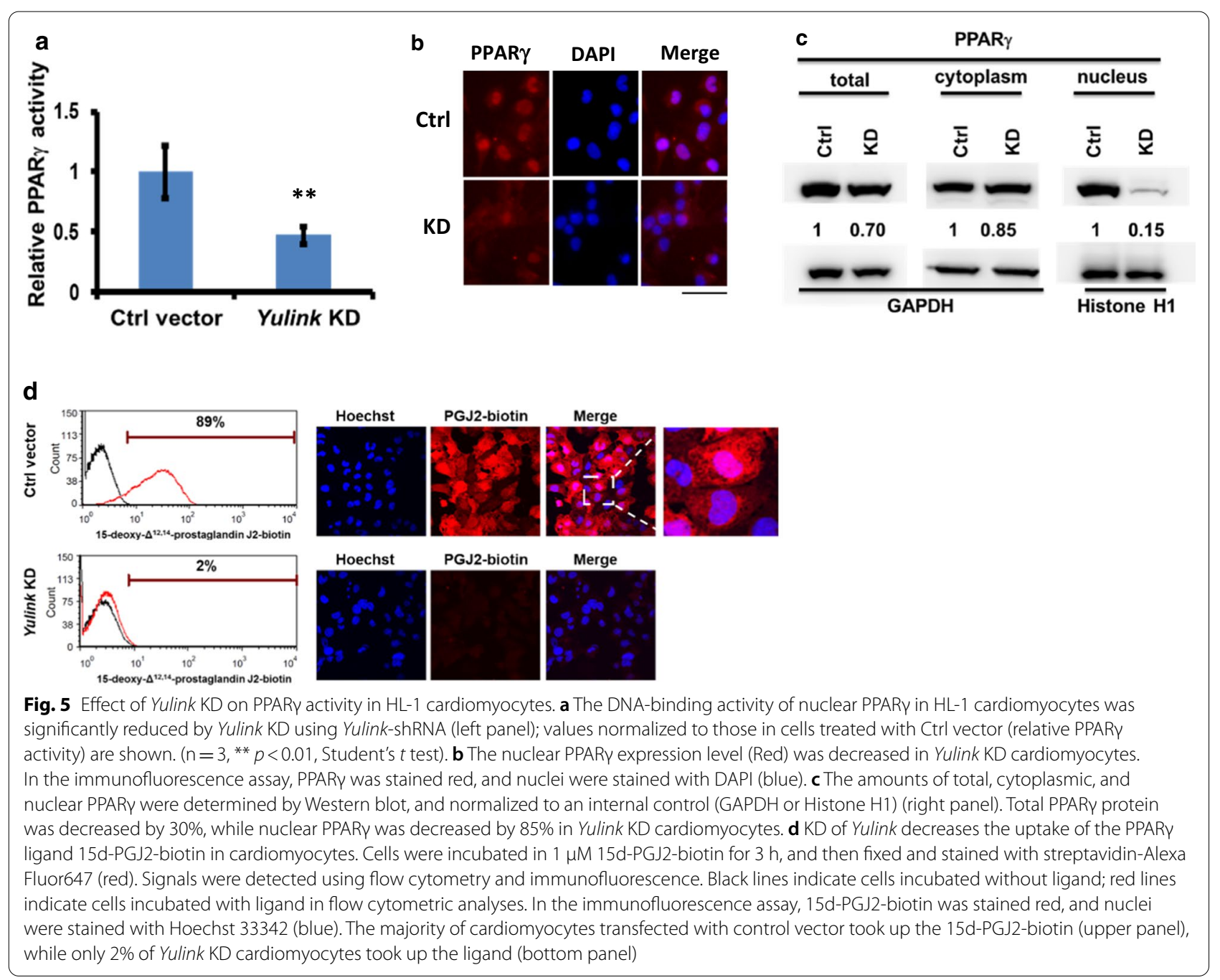

Yulink KD resulted in diminished PPAR $\gamma$ DNA-binding and nuclear PPAR $\gamma$ protein level in HL-1 cardiomyocytes suggest that Yulink may involve in the nuclear import of PPARY.

The ligands for PPAR $\gamma$ are known to include fatty acids, arachidonic acid metabolites, and thiazolidinediones, such as rosiglitazone and pioglitazone $[28,31]$. In addition, 15-deoxy- $\Delta^{12,14}$-prostaglandin J2 (15d-PGJ2) has been reported as an endogenous ligand for PPAR $\gamma$ activation $[9,15]$. Therefore, we used the biotinylated 15d-PGJ2 to characterize the ligand uptake in Yulink KD cardiomyocytes by flow cytometry and immunofluorescence (Fig. 5d). The results showed that $89 \%$ of the fluorescent 15d-PGJ2-biotin was taken up by control vector-treated cardiomyocytes, but only $2 \%$ was found in Yulink KD cardiomyocytes (Fig. 5d). In the immunofluorescence assay, in which 15d-PGJ2-biotin was stained with streptavidin-Alexa Fluor647 (red), and nuclei were stained with Hoechst 33342 (blue), red signals were observed in the cytoplasm and nuclei of control cardiomyocytes, while no red signals were detected in Yulink KD cardiomyocytes (Fig. 5d). These findings indicated that Yulink KD block the ligands of PPARY into cells and result in a decreased nuclear import of PPARY.

\section{PPAR $\gamma$ regulates Serca2 expression in mouse HL-1 cardiomyocytes}

To examine whether the Yulink regulate Serca2 expression through PPAR $\gamma$ pathway, Yulink KD cardiomyocytes were treated with $50 \mu \mathrm{M}$ rosiglitazone (a PPAR $\gamma$ agonist) for 6 h. As showed in Fig. 6a, the relative Serca 2 mRNA expressions were 1.09 and 2.57 in the presence of 10 and $50 \mu \mathrm{M}$ rosiglitazone, respectively, compared to the control in the absence of the rosiglitazone. In addition, the SERCA2 protein level could be enhanced to 1.5 folds in control vector-treated cardiomyocytes by $50 \mu \mathrm{M}$ rosiglitazone treatment for $6 \mathrm{~h}$. Furthermore, in Yulink KD cardiomyocytes, the decreased expression of Serca 2 can be 


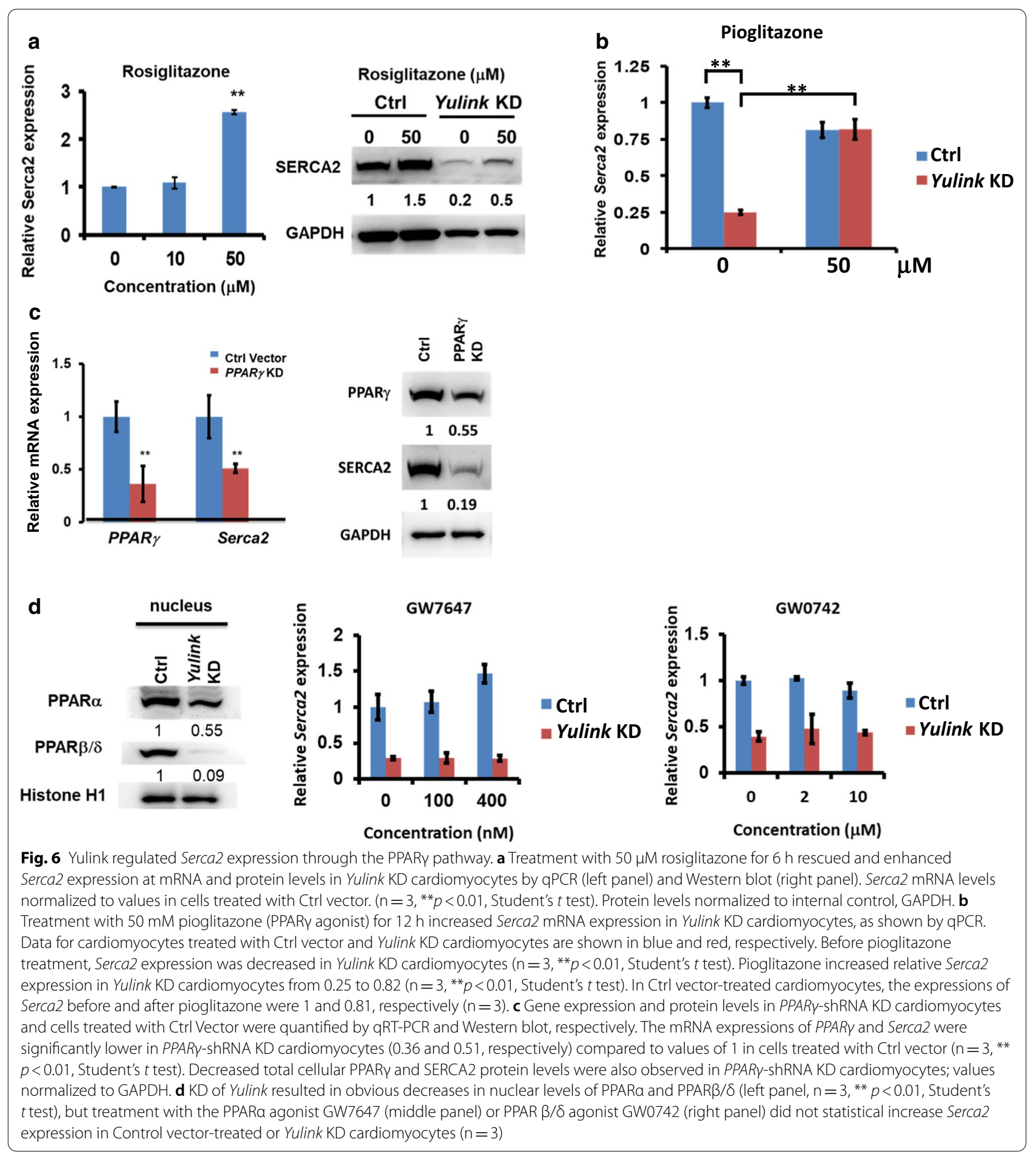

rescued from 0.2 to 0.5 folds (Fig. 6a). In parallel, treatment with another PPAR $\gamma$ agonist pioglitazone $(50 \mu \mathrm{M})$ for $12 \mathrm{~h}$ almost completely rescued Serca 2 mRNA expression (Fig. 6b). PPAR $\gamma$ agonists enhanced the SERCA2 expression in the control- and Yulink KD cardiomyocytes, suggest that the down regulation of Yulink resulted in a decreased SERCA2 expression may through PPAR $\gamma$ pathway.

To confirm the transcription factor PPAR involved in the Serca 2 expression in cardiomyocytes. HL-1 cells were transduced with lentivirus expressing shRNA against PPARy. Quantitative PCR and western blotting analysis 
of the transduced cells confirmed a PPARy knockdown efficiency of $\sim 70 \%$ (Fig. $6 \mathrm{c}$ ). The relative mRNA and protein levels of Serca2 were also significantly reduced in these PPARY KD cells (Fig. 6c). These results confirmed that the regulation of the Serca2 expression by Yulink is mediated via PPAR $\gamma$ in HL-1 cardiomyocytes.

We also observed decreased levels of PPAR $\alpha$ and PPAR $\beta / \delta$ in Yulink KD cardiomyocytes (Fig. 6d). Treatment with PPAR $\alpha$ and PPAR $\beta / \delta$ agonists, GW7647 and GW0742, however, did not increase Serca2 expression in control or Yulink KD cardiomyocytes (Fig. 6d), suggesting that PPAR $\alpha$ or PPAR $\beta / \delta$ does not involved in Serca 2 expression. Therefore, these results highlight the involvement of Yulink with PPARY in regulating Serca2 expression in HL-1 cardiomyocytes.

PPARY has been shown to bind directly to the PPAR response element in the promoter of the SERCA2 gene of pancreatic islet cells [16]. In this study, KD of PPARy resulted in significant decreases in the expression of Serca 2 mRNA and protein in both normal and Yulink KD cardiomyocytes. Down-regulation of Yulink resulted in a significant reduction in PPAR $\gamma$ DNA binding activity and protein level in the nuclei, demonstrating the role of PPARY in Yulink-mediated transcriptional regulation of Serca2. Additionally, PPAR $\gamma$ agonists were found to enhance the expression of Serca2 in both normal and Yulink KD cardiomyocytes. But, treatment with PPAR $\alpha$ or PPAR $\beta / \delta$ agonists did not protect against the Yulink KD-induced reduction of SERCA2, suggesting the specificity and dependence on PPAR $\gamma$.

\section{PPARY over-expression rescued the phenotypes of Yulink $\mathrm{KD}$ cells}

In order to study whether the PPARY over-expression (OE) rescued the phenotypes of Yulink KD cells, control (Ctrl) or PPARy plasmid with BFP as expression marker were transfected into Yulink KD cells, and we then analyzed $\mathrm{Ca}^{2+}$ cycling. As compared to Yulink KD control cells, the intracellular $\mathrm{Ca}^{2+}$ cycling waveforms became normal, when these KD cells were over-expressed with PPARY (Fig. 4a). In addition, the results of $\mathrm{Ca}^{2+}$ sparks analysis were consistent with the increase of $\mathrm{Ca}^{2+}$ transient amplitudes ( $3.2 \pm 0.3$ for PPAR $y$-OE, blue bar, vs. $1.9 \pm 0.35$ for Ctrl, black bar) (Fig. 4a). The cells with $P P A R$-OE also exhibited a decrease of the percentages of irregular $\mathrm{Ca}^{2+}$ transients $(10 \pm 2 \%$ for PPAR $y$-OE, blue bar, vs. $27 \pm 3 \%$ for Ctrl, black bar) and the reduction of the $\mathrm{Ca}^{2+}$ decay rate $(450 \pm 51 \mathrm{~ms}$ for PPAR $\mathrm{O}$-OE, blue bar, vs. $605 \pm 47 \mathrm{~ms}$ for Ctrl, black bar) (Fig. 4a). The level of $\mathrm{Ca}^{2+}$ transient amplitudes, the percentages of irregular $\mathrm{Ca}^{2+}$ transients, and the $\mathrm{Ca}^{2+}$ decay (Tau) rate were all similar between Ctrl (Fig. 3b) and over-expression of PPARy cells. These data indicate that the PPAR $y$-OE rescued the phenotypes of Yulink KD cells, suggesting involvement of Yulink with PPAR $\gamma$ in regulating Serca2 expression in HL-1 cardiomyocytes.

\section{SERCA2 over-expression rescued the phenotypes of Yulink $\mathrm{KD}$ cells}

In order to examine whether the SERCA2 over-expression (SERCA2-OE) rescued the phenotypes of Yulink KD cells, control vector (Ctrl) or SERCA2 plasmids were electroporated into Yulink KD cells with Neon electroporation system. As compared to Yulink KD control cells, the intracellular $\mathrm{Ca}^{2+}$ cycling waveforms became normal, when these KD cells were over-expressed with SERCA2 (Fig. 4b). In addition, the results of $\mathrm{Ca}^{2+}$ sparks analysis were consistent with the increase of $\mathrm{Ca}^{2+}$ transient amplitudes $(3.2 \pm 0.45$ for SERCA2-OE, gray bar, vs. $2.02 \pm 0.3$ for Ctrl, black bar) (Fig. 4b). The cells with SERCA2-OE also exhibited a decrease of the percentages of the irregular $\mathrm{Ca}^{2+}$ transients $(11 \pm 3 \%$ for SERCA2-OE, gray bar, vs. $32 \pm 5 \%$ for Ctrl, black bar) and the reduction of the $\mathrm{Ca}^{2+}$ decay rate ( $412 \pm 50 \mathrm{~ms}$ for SERCA2-OE, gray bar, vs. $635 \pm 78 \mathrm{~ms}$ for Ctrl, black bar) (Fig. 4b). The level of $\mathrm{Ca}^{2+}$ transient amplitudes, the percentages of irregular $\mathrm{Ca}^{2+}$ transients, and the $\mathrm{Ca}^{2+}$ decay (Tau) rate were all similar between Ctrl (Fig. 3b) and over-expression of SERCA2 cells. These data indicate that the SERCA2-OE rescued the phenotypes of Yulink KD cells, suggesting a specific control for SERCA2 expression by Yulink in regulating calcium cycling in HL-1 cardiomyocytes.

\section{Yulink KD induces irregular $\mathrm{Ca}^{2+}$ cycling in human cardiomyocytes derived from iPSC}

To investigate whether the YULINK also involves in intracellular $\mathrm{Ca}^{2+}$ cycling in human cardiomyocytes, we analyzed $\mathrm{Ca}^{2+}$ cycling in human iPSC-derived cardiomyocytes using fluorescent $\mathrm{Ca}^{2+}$ dye Rhod-2 AM. Compared to control, the YULINK KD iPSC-derived human cardiomyocytes showed defective intracellular $\mathrm{Ca}^{2+}$ cycling with significant higher arrhythmia-like waveforms (38.4\% vs. $12.5 \%$ for control) (red arrows in Fig. 7a, b), indicative of the $\mathrm{Ca}^{2+}$ transient irregularities. In addition, smaller $\mathrm{Ca}^{2+}$ transient amplitudes $(1.87 \pm 0.31$ for YULINK KD vs. $2.89 \pm 0.34$ for control) (Fig. 7c) and slower $\mathrm{Ca}^{2+}$ decay rate $(521 \pm 30 \mathrm{~ms}$ for YULINK KD vs. $351 \pm 21 \mathrm{~ms}$ for control) (Fig. 7d) were also found. These observations of the $\mathrm{Ca}^{2+}$ transients of human iPSC-derived cardiomyocytes are consistent with the results using mouse HL-1 cardiomyocytes, indicating that irregular $\mathrm{Ca}^{2+}$ cycling is a feature of cardiomyocytes for mouse and human, when Yulink was knockdown.

Furthermore, the contractile function of the control and YULINK KD cardiomyocytes was also examined. The cell contraction rate was counted under a phase-contrast 


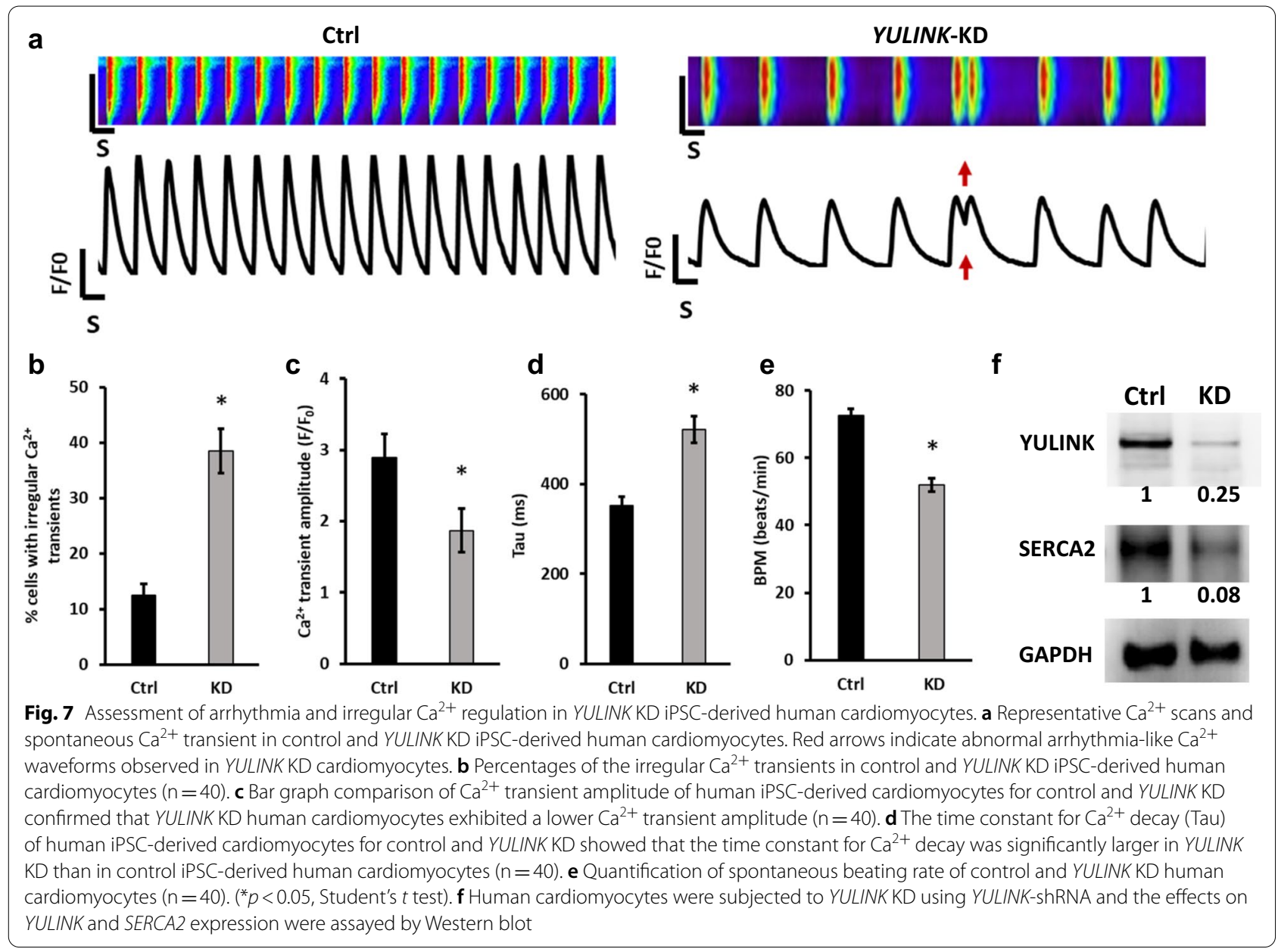

microscope, it was found that YULINK KD resulted in reduction of spontaneous beating rate, as shown with a reduced beating frequency by $28.3 \%$ (Fig. $7 \mathrm{e}$ ).

To determine the SERAC2 expression in the YULINK KD human cardiomyocytes, western blotting analysis was performed. It was found that there were approximately 90\% reduction of SERCA2 expression in the YULINK KD cardiomyocytes (Fig. 7f). These results imply that YULINK regulates SERCA2 expression and intracellular $\mathrm{Ca}^{2+}$ cycling in human cardiomyocytes.

\section{Discussions}

In this study, we have demonstrated that Yulink is highly conserved in zebrafish, mouse, and human. It was expressed in zebrafish embryo ubiquitously from zygote stage to larval stage and expressed in heart region starting from $1 \mathrm{dpf}$. The yulink KD morphants in zebrafish exhibited pericardial edema, slower heart rate, and reduced cardiac output. Besides, we also observed that down-regulation of Yulink in the mouse and iPSC-derived human cardiomyocytes exhibited defective intracellular $\mathrm{Ca}^{2+}$ cycling. Importantly it was observed that YULINK, PPARY or SERCA2 over-expression specifically rescued the phenotypes of Yulink KD cells. These results thus suggest that Yulink is involved in intracellular $\mathrm{Ca}^{2+}$ cycling in cardiomyocytes.

$\mathrm{Ca}^{2+}$ cycling is crucial for excitation-contraction coupling of cardiomyocytes and is essential in the electrical signaling of cardiomyocytes. Abnormal $\mathrm{Ca}^{2+}$ cycling is linked to arrhythmogenesis, which is associated with cardiac disorders and heart failure [10]. KD of Yulink in mouse and human cardiomyocytes displayed a decrease in SERCA2 expression and exhibited higher $\mathrm{Ca}^{2+}$ transient irregularities which are accompanied with the triggered arrhythmia, defective intracellular $\mathrm{Ca}^{2+}$ cycling with a reduced $\mathrm{Ca}^{2+}$ transient amplitudes, and slower $\mathrm{Ca}^{2+}$ decay rate. In addition, YULINK, $P P A R Y$ or SERCA2 over-expression restored these phenotypes of mouse Yulink KD cells, indicating that the Yulink-shRNA used in our studies was specific and the observed defects in cells were Yulink-dependent. 
When SERCA2 was deleted in mouse heart using the tamoxifen-inducible Cre, The Tau of $\mathrm{Ca}^{2+}$ transient was increased by 90 to $118 \%$ in SERCA2-deficient cardiomyocytes [1, 19]. Additionally, it is known that the decreases in SERCA2 expression resulted in a diminished $\mathrm{Ca}^{2+}$ content in the sarcoplasmic reticulum, which reduced systolic $\mathrm{Ca}^{2+}$ release and impairment of myocardial contractility [10]. Therefore, decrease in Yulink function may play an important role in susceptibility to heart arrhythmia via impairment of cardiac SERCA2 activity.

Our studies indicated that knockdown of Yulink resulted in a decrease of nuclear PPAR $\alpha$ and $\beta / \delta$ levels in HL-1 cardiomyocytes. Previously, it was reported that PPARs were major executors for modulating homeostasis of glucoses and lipids in heart [3]. Overexpression of PPAR $\alpha$ induced several target genes involved in fatty acid utilization and increased fatty acid uptake and oxidation in heart [8]. On the other hand, PPAR $\alpha$ null mice exhibited an increase in glucose transporter expression and glucose uptake $[5,23]$. Mice with cardiac-specific deletion of $P P A R \beta / \delta$ were shown to exhibit severe impairments in myocardial fatty acid oxidation gene expression and increased cardiac lipid accumulation [6]. Therefore, the decreased nuclear PPAR $\alpha$ and PPAR $\beta / \delta$ levels observed in Yulink KD cardiomyocytes would suggest that Yulink may has other important functions in the maintenance of glucose and lipid homeostasis via regulating PPAR $\alpha$ or PPAR $\beta / \delta$ activities.

Some natural ligands can bind PPAR $\gamma$, like unsaturated fatty acid, 15-Hydroxyeicosatetraenoic acid, 9and 13-hydroxyoctadecadienoic acid or PGJ2 [18]. It is unknown which ligand is required for cardiomyocytes and entry into cells via Yulink. Transcriptional activity of PPAR $\gamma$ is regulated primarily by ligand binding [33] and $15 \mathrm{~d}-\mathrm{PGJ} 2$ is thought to be the most potent endogenous ligand for PPARY $[9,36]$. The 15d-PGJ2 was detected in exosomes; and exosomes were internalized and accumulated in an endosomal compartment [30]. Here, we used 15d-PGJ2-biotin as PPARY ligand and KD of Yulink blocked the entry of ligand into cells. Therefore, Yulink KD resulted in a reduced nuclear import of PPAR $\gamma$, a decreased SERCA2 expression, and abnormal $\mathrm{Ca}^{2+}$ cycling in the mouse HL-1 cardiomyocytes. Furthermore, it was reported that PPARY bound a PPAR response element in the -259 bp proximal region of SERCA2 promoter in pancreatic cells, based on luciferase reporter assay, EMSA, and chromatin immunoprecipitation [16]. In addition, the $S E R C A 2$ promoter region of rabbit, rat, mouse and human all displayed the PPARY binding site [16]. However, there was no direct evidence to demonstrate a binding of PPAR in cardiomyocytes. We would await for studies in the future to investigate in details how Yulink modulates uptake of ligand for PPAR $\gamma$, thus regulating SERCA2 in cells. In addition to PPAR $\gamma$ signaling, other pathways might be impaired when Yulink was knockdown, indicating the need for future studies to validate detailed mechanism.

\section{Conclusions}

Deficiency of yulink caused cardiac dysfunction in zebrafish, manifested by pericardial edema, decreased beating rate and cardiac output. In addition, down regulation of Yulink in mouse and human iPSC-derived cardiomyocytes resulted in greater $\mathrm{Ca}^{2+}$ transient irregularities including defective intracellular $\mathrm{Ca}^{2+}$ cycling, reduced $\mathrm{Ca}^{2+}$ transient amplitudes, and slower $\mathrm{Ca}^{2+}$ decay rate, thereby triggering arrhythmia. Besides, YULINK, PPARY or SERCA2 over-expression rescued these phenotypes of mouse Yulink KD cells. Mechanistically, deficiency of Yulink reduced expression of cardiac SERCA2 mediated by PPAR $\gamma$ nucleus entry.

Importantly, our results highlight the involvement of Yulink with PPAR $\gamma$ in regulating SERCA2 expression, which may shed light on many debates about the risks and benefits of PPAR $\gamma$ agonists in clinical use. Finally, this Yulink gene was first identified through comparative evolutionary genomics analysis and reverse screening involving genetic knockdown in zebrafish. The strategies of using the initial observations in zebrafish for the identification of biological functions in mouse HL-1 cardiomyocytes and human iPSC-derived cardiomyocytes provide new paradigm for the study of diseases mechanisms of other specific/novel genes.

\section{Supplementary Information}

The online version contains supplementary material available at https://doi. org/10.1186/s12929-020-00701-7.

Additional file 1: Video

Additional file 2: Fig. S1. Prediction of secondary structure for YULINK. Fig. S2. Similar phenotypes of yulink knockdown were observed in embryos after microinjection with $\mathrm{MO}$ that targeted against the splicing site or start site. Fig. S3. The expressions of heart rate-related genes were reduced in yulink KD morphants. Fig. S4. The phenotypes of the morphants were rescued via over-expression of Yulink.

Acknowledgements

We would like to thank the excellent technical support from the Core Facility of the Institute of Cellular and Organismic Biology, Academia Sinica.

\section{Authors' contributions}

MWK, HHT, SHW, ALY and JY conceived of the experiments, interpreted results and wrote the manuscript. MWK, HHT and YY C conducted the experiments, and performed the statistical analyses. All authors read and approved the final manuscript.

\section{Funding}

This work was supported by grants MOST 109-2321-B-182A-005 from the Ministry of Science and Technology of Taiwan, CMRPG3F0971 to CMRPG3F0973, and OMRPG3C0046 from Chang Gung Medical Foundation. 


\section{Availability of supporting data}

All data generated or analyzed during this study are included in this article.

\section{Ethical approval and consent to participate}

Breeding and maintenance of TL strain zebrafish, as well as the collection and staging of embryos, were performed in accordance with standard procedures and approved by the Academia Sinica Institutional Animal Care and Utilization Committee.

\section{Consent for publication}

Not applicable.

\section{Competing interests}

The author declares that they have no competing interests.

\section{Author details}

${ }^{1}$ Institute of Stem Cell and Translational Cancer Research, Chang Gung Memorial Hospital at Linkou, Taoyuan 333, Taiwan. ${ }^{2}$ Department of Pediatrics, University of California, San Diego, CA, USA. ${ }^{3}$ Institute of Cellular and Organismic Biology, Academia Sinica, Taipei, Taiwan.

Received: 2 July 2020 Accepted: 21 December 2020

Published online: 11 January 2021

\section{References}

1. Andersson KB, Birkeland JA, Finsen AV, Louch WE, Sjaastad I, Wang Y, Chen J, Molkentin JD, Chien KR, Sejersted OM, Christensen G. Moderate heart dysfunction in mice with inducible cardiomyocyte-specific excision of the Serca2 gene. J Mol Cell Cardiol. 2009;47(2):180-7.

2. Bar-Peled L, Chantranupong L, Cherniack AD, Chen WW, Ottina KA, Grabiner BC, Spear ED, Carter SL, Meyerson M, Sabatini DM. A tumor suppressor complex with GAP activity for the Rag GTPases that signal amino acid sufficiency to mTORC1. Science. 2013:340(6136):1100-6.

3. Barger PM, Kelly DP. PPAR signaling in the control of cardiac energy metabolism. Trends Cardiovasc Med. 2000;10(6):238-45.

4. Burridge PW, Matsa E, Shukla P, Lin ZC, Churko JM, Ebert AD, Lan F, Diecke S, Huber B, Mordwinkin NM, Plews JR, Abilez OJ, Cui B, Gold JD, Wu JC. Chemically defined generation of human cardiomyocytes. Nat Methods. 2014;11(8):855-60.

5. Campbell FM, Kozak R, Wagner A, Altarejos JY, Dyck JR, Belke DD, Severson DL, Kelly DP, Lopaschuk GD. A role for peroxisome proliferator-activated receptor alpha (PPARalpha) in the control of cardiac malonyl-CoA levels: reduced fatty acid oxidation rates and increased glucose oxidation rates in the hearts of mice lacking PPARalpha are associated with higher concentrations of malonyl-CoA and reduced expression of malonyl-CoA decarboxylase. J Biol Chem. 2002;277(6):4098-103.

6. Cheng L, Ding G, Qin Q, Huang Y, Lewis W, He N, Evans RM, Schneider MD, Brako FA, Xiao Y, Chen YE, Yang Q. Cardiomyocyte-restricted peroxisome proliferator-activated receptor-delta deletion perturbs myocardial fatty acid oxidation and leads to cardiomyopathy. Nat Med. 2004:10(11):1245-50.

7. Ebert AM, Hume GL, Warren KS, Cook NP, Burns CG, Mohideen MA, Siegal G, Yelon D, Fishman MC, Garrity DM. Calcium extrusion is critical for cardiac morphogenesis and rhythm in embryonic zebrafish hearts. Proc Natl Acad Sci USA. 2005:102(49):17705-10.

8. Finck BN, Lehman JJ, Leone TC, Welch MJ, Bennett MJ, Kovacs A, Han X, Gross RW, Kozak R, Lopaschuk GD, Kelly DP. The cardiac phenotype induced by PPARalpha overexpression mimics that caused by diabetes mellitus. J Clin Invest. 2002;109(1):121-30.

9. Forman BM, Tontonoz P, Chen J, Brun RP, Spiegelman BM, Evans RM. 15-Deoxy-delta 12, 14-prostaglandin $\mathrm{J} 2$ is a ligand for the adipocyte determination factor PPAR gamma. Cell. 1995;83(5):803-12.

10. Frank KF, Bolck B, Erdmann E, Schwinger RH. Sarcoplasmic reticulum $\mathrm{Ca}^{2+}$-ATPase modulates cardiac contraction and relaxation. Cardiovasc Res. 2003;57(1):20-7.

11. Hirayama $Y$, Saitoh $H$, Atarashi $H$, Hayakawa $H$. Electrical and mechanical alternans in canine myocardium in vivo. Dependence on intracellular calcium cycling. Circulation. 1993;88(6):2894-902.
12. Iida T, Lilly MA. missing oocyte encodes a highly conserved nuclear protein required for the maintenance of the meiotic cycle and oocyte identity in Drosophila. Development. 2004;131(5):1029-39.

13. Issemann I, Green S. Activation of a member of the steroid hormone receptor superfamily by peroxisome proliferators. Nature. 1990;347(6294):645-50.

14. Jou CJ, Arrington CB, Barnett S, Shen J, Cho S, Sheng X, McCullagh PC, Bowles NE, Pribble CM, Saarel EV, Pilcher TA, Etheridge SP, Tristani-Firouzi M. A functional assay for sick sinus syndrome genetic variants. Cell Physiol Biochem. 2017;42(5):2021-9.

15. Kliewer SA, Lenhard JM, Willson TM, Patel I, Morris DC, Lehmann JM. A prostaglandin $\mathrm{J} 2$ metabolite binds peroxisome proliferator-activated receptor gamma and promotes adipocyte differentiation. Cell. 1995;83(5):813-9.

16. Kono T, Ahn G, Moss DR, Gann L, Zarain-Herzberg A, Nishiki Y, Fueger PT, Ogihara T, Evans-Molina C. PPAR-gamma activation restores pancreatic islet SERCA2 levels and prevents beta-cell dysfunction under conditions of hyperglycemic and cytokine stress. Mol Endocrinol. 2012;26(2):257-71.

17. Kuo MW, Wang SH, Chang JC, Chang CH, Huang $\sqcup$, Lin HH, Yu AL, Li WH, Yu J. A novel puf-A gene predicted from evolutionary analysis is involved in the development of eyes and primordial germ-cells. PLOS ONE. 2009;4(3):e4980.

18. Lee WS, Kim J. Peroxisome proliferator-activated receptors and the heart: lessons from the past and future directions. PPAR Res. 2015;2015:271983.

19. Li L, Louch WE, Niederer SA, Aronsen JM, Christensen G, Sejersted OM, Smith NP. Sodium accumulation in SERCA knockout-induced heart failure. Biophys J. 2012;102(9):2039-48.

20. Nekrutenko A, Chung WY, Li WH. ETOPE: Evolutionary test of predicted exons. Nucleic Acids Res. 2003a;31(13):3564-7.

21. Nekrutenko A, Chung WY, Li WH. An evolutionary approach reveals a high protein-coding capacity of the human genome. Trends Genet. 2003b;19(6):306-10.

22. Nekrutenko A, Makova KD, Li WH. The $K(A) / K(S)$ ratio test for assessing the protein-coding potential of genomic regions: an empirical and simulation study. Genome Res. 2002;12(1):198-202.

23. Panagia M, Gibbons GF, Radda GK, Clarke K. PPAR-alpha activation required for decreased glucose uptake and increased susceptibility to injury during ischemia. Am J Physiol Heart Circ Physiol. 2005;288(6):H2677-2683.

24. Pastore JM, Girouard SD, Laurita KR, Akar FG, Rosenbaum DS. Mechanism linking T-wave alternans to the genesis of cardiac fibrillation. Circulation. 1999:99(10):1385-94

25. Periasamy M, Kalyanasundaram A. SERCA pump isoforms: their role in calcium transport and disease. Muscle Nerve. 2007;35(4):430-42.

26. Pruvot EJ, Katra RP, Rosenbaum DS, Laurita KR. Role of calcium cycling versus restitution in the mechanism of repolarization alternans. Circ Res 2004;94(8):1083-90.

27. Roden DM, Balser JR, George AL Jr, Anderson ME. Cardiac ion channels. Annu Rev Physiol. 2002;64:431-75.

28. Sakamoto J, Kimura H, Moriyama S, Odaka H, Momose Y, Sugiyama Y, Sawada H. Activation of human peroxisome proliferator-activated receptor (PPAR) subtypes by pioglitazone. Biochem Biophys Res Commun. 2000;278(3):704-11.

29. Stieber J, Herrmann S, Feil S, Loster J, Feil R, Biel M, Hofmann F, Ludwig A. The hyperpolarization-activated channel HCN4 is required for the generation of pacemaker action potentials in the embryonic heart. Proc Natl Acad Sci USA. 2003:100(25):15235-40.

30. Subra C, Grand D, Laulagnier K, Stella A, Lambeau G, Paillasse M, De Medina P, Monsarrat B, Perret B, Silvente-Poirot S, Poirot M, Record M. Exosomes account for vesicle-mediated transcellular transport of activatable phospholipases and prostaglandins. J Lipid Res. 2010;51(8):2105-20.

31. Tontonoz P, Spiegelman BM. Fat and beyond: the diverse biology of PPARgamma. Annu Rev Biochem. 2008;77:289-312.

32. Tsai CT, Chiang FT, Tseng CD, Yu CC, Wang YC, Lai LP, Hwang JJ, Lin $J$ L. Mechanical stretch of atrial myocyte monolayer decreases sarcoplasmic reticulum calcium adenosine triphosphatase expression and increases susceptibility to repolarization alternans. J Am Coll Cardiol. 2011;58(20):2106-15.

33. Ulivieri C, Baldari CT. The potential of peroxisome proliferator-activated receptor gamma (PPARgamma) ligands in the treatment of hematological malignancies. Mini Rev Med Chem. 2007;7(9):877-87. 
34. Vangheluwe P, Louch WE, Ver Heyen M, Sipido K, Raeymaekers L, Wuytack F. Ca ${ }^{2+}$ transport ATPase isoforms SERCA2a and SERCA2b are targeted to the same sites in the murine heart. Cell Calcium. 2003;34(6):457-64.

35. Westerfield M. The Zebrafish book: a guide for the laboratory use of Zebrafish (Danio rerio). Eugene: Univ. of Oregon Press; 1995.

36. Willson TM, Brown PJ, Sternbach DD, Henke BR. The PPARs: from orphan receptors to drug discovery. J Med Chem. 2000;43(4):527-50.
37. Xu C, Min J. Structure and function of WD40 domain proteins. Protein Cell. 2011;2(3):202-14

\section{Publisher's Note}

Springer Nature remains neutral with regard to jurisdictional claims in published maps and institutional affiliations.
Ready to submit your research? Choose BMC and benefit from:

- fast, convenient online submission

- thorough peer review by experienced researchers in your field

- rapid publication on acceptance

- support for research data, including large and complex data types

- gold Open Access which fosters wider collaboration and increased citations

- maximum visibility for your research: over 100M website views per year

At BMC, research is always in progress.

Learn more biomedcentral.com/submissions 